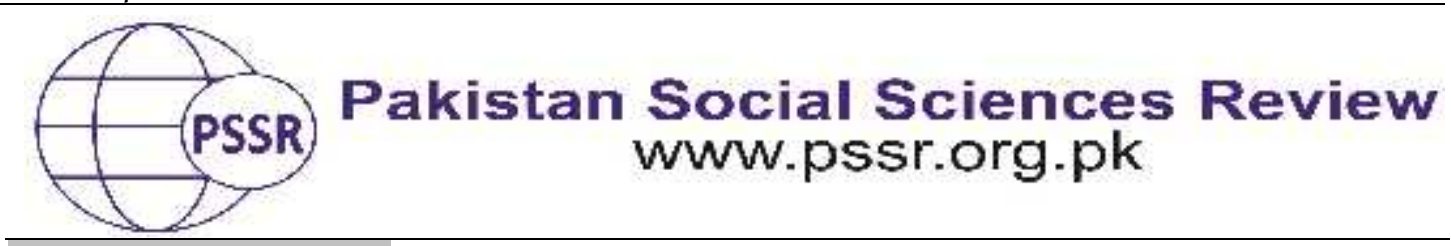

RESEARCH PAPER

\title{
Frame Markers as Metadiscoursal Features in Pakistani English Newspapers' Editorials: A Corpus-Based Study
}

\author{
Ali Raza Siddique ${ }^{1}$ Muhammad Ahmad ${ }^{2}$ Sumera Shan Ahmad ${ }^{3}$
}

1. PhD Candidate, Department of Applied Linguistics, Government College University, Faisalabad, Pakistan

2. PhD Candidate, Department of Applied Linguistics, Government College University, Faisalabad, Pakistan

3. Lecturer, Department of Linguistics and Communications, University of Management and Technology, Lahore, Pakistan

\begin{tabular}{|c|c|}
\hline APE & \\
\hline $\operatorname{Rec}$ & \multirow{15}{*}{$\begin{array}{l}\text { Frame markers are said to be used as a tool to organize and } \\
\text { frame the discourse in a text. This study, therefore, examines } \\
\text { the use of frame markers in the newspaper editorials. Being a } \\
\text { corpus-based study, it develops the corpora from } 1000 \\
\text { editorials published in four Pakistani English language } \\
\text { newspapers ( } 250 \text { editorials each) which are (the corpora) } \\
\text { analyzed through AntConc } 3.4 .4 .0 \text { following interpersonal } \\
\text { model by Hyland (2005). The results indicate that the } \\
\text { editorialists in 'The Frontier', 'The Dawn', 'The News', and } \\
\text { 'The Express Tribune' use frame markers to constitute the } \\
\text { meaning contextually in the minds of the readers. However, } \\
\text { the editorialists in The Frontier are observed to use frame } \\
\text { markers more than any other newspaper in the study. The } \\
\text { study also proposes a list of } 121 \text { frame markers from Hyland } \\
\text { (2005) and textinspector.com which will help the future } \\
\text { researchers to study frame markers in different genera }\end{array}$} \\
\hline & \\
\hline & \\
\hline . & \\
\hline & \\
\hline & \\
\hline & \\
\hline & \\
\hline & \\
\hline & \\
\hline & \\
\hline & \\
\hline ers & \\
\hline onding & \\
\hline & \\
\hline
\end{tabular}

\section{Introduction}

The term 'metadiscourse' states that the "aspects of a text explicitly organize a discourse or the writer's stance towards either its content or the reader" (Hyland, 2000, p. 14). This is extensively dependent on the opinion that the action of writing is a social conduct based on the connections among the reader, writer and social context (Hyland, 2000; Nystrand, 1986; Thompson, 2001).

Nevertheless, in the early 1980s, Sinclair was alone to focus on the essence of interactional features of a language. At the time of its beginning, the ways of research in language was used to bargain the relationships and support interaction was greatly left to sociologists and sociolinguistics. In fact, the work of sociologists 
like Bateson (1972) and Goffman (1974) on 'frame' was considered as an important development leading to linguistic conceptions of the metadiscourse.

Gholami, Tajalli and Shokrpour (2014) demonstrated the categorization of interpersonal metadiscourse. They highlighted the classification of 'frame markers' (FMs) in their study to express the functions of interactive metadiscourse. They showed FMs in terms of sequence markers, label stages, announce goals and topic shift. They also shared transition markers as additive, causal, adversative and temporal. They took 35 medical articles in English and their translation in Persian following Hyland's (2005) taxonomy. They ultimately concluded that English medical articles employed more interactional resources than their Persian translation. The said study assists to explore 'FMs' in the Pakistani English newspaper editorials. FMs state the use of (non)propositional items in spoken and written language which shows the connection between the writers and readers in a text. The prior works on 'metadiscourse' apparently differentiate into two categories i.e. interactive and interactional metadiscoursal categories. Past studies (e.g. Hyland \& Tse, 2004; Siddique, 2017; Siddique, Mahmood \& Iqbal, 2018) reported IFs being helpful in organizing the text and further enhancing the coherence and cohesion, whereas interactional features convey authors' attitudes about the text and assess the propositional material (Hyland, 2005; Oskouei, 2011). This study, therefore, investigates the FMs as IFs which are used to announce goals, sequence the text, shift topic, and label stages by the writer in the text (Hyland, 2005; Siddique, Mahmood \& Iqbal, 2018). In this study, FMs are classified and defined in terms of: (a) announce goals that are used to announce discourse goals in the text, e.g. aim, desire to, in this part, and here I do this; (b) sequencing markers that are used to organize and establish discourse hierarchy in the text to convey the intended meanings, i.e. accordingly, even though, on the contrary, and on the other hand; (c) topic shifting devices that are used to manipulate discourse and situation through features like; back to, in regard to, to look more, and closely, and; (d) labeling stage is a term that is used to tell the current position of the narrator in the discourse through; now, in short, at this stage, and for the moment (Hyland, 2005; Siddique, 2017; Siddique, Mahmood \& Iqbal, 2018). Thus, this study aims to explore the ways the writers frame their narrative or discourse to convey intended meanings and manipulate the audience through framing features. In this regard following research questions have been raised:

1) What are the occurrences of FMs in Pakistani English newspaper editorials?

2) What are the functions of FMs in Pakistani English newspaper editorials?

3) What are the similarities and differences of FMs in Pakistani English newspaper editorials?

Editorials are opinion articles written by the editorial staff to display the influence of the public opinion through 'communicative purpose' that is fulfilled by creating persuasiveness in language which develops the 'social function' (see 
Cheng, 2010). Moreover, the editorials are argumentative and persuasive in nature. This feature is demanded in a text's conscious structuring to construct a relation between the editorialists and the audience. Beaugrande and Dressler (1981) explained argumentative texts as "those utilized to promote the acceptance or evaluation of certain beliefs or ideas as true vs. false, or positive vs. negative. Conceptual relations such as reason, significance, volition, value and opposition should be frequent" (p. 184). For Williams (1981) this persuasive feature might affect the quantity of interactional items employed in addition to strengthen this relationship. It is perceived that the use of interpersonal metadiscourse is greatly seen in argumentative writing.

Van Dijk (1995) explored that the role of editorials was considered to form and change the public views or opinion. Editorials are supposed to be helpful in setting political agenda, to influence the decision making, social debate, and form political and social activities. He perceived 'editorial opinion' as institutional, not personal. Though, opinion articles are commonly nameless. These articles provide specific magazine or newspapers' reflection as tend to be derived from social representations, rather than from the personal experiences or opinions of the editor.

Another study on an interactive MM in 9/11 Persian news reports, 30 news articles were chosen from Persian elite and widely read newspapers (Yazdani, 2014), and the results as Iranian journalists preferred to use transitions heavily in their reports, whereas the least employment of interactive metadiscourse belonged to FMs. The absent marker in Persian news articles was endophorics. Transitions were the most frequently used markers due to formal style of writing in the newspaper discourse, whereas FMs were the least employed metadiscourse in this genre. Moreover, endophoric markers were absent in Persian news articles. This study led to answer the second question in this study which is mainly inspired from Gholami, Tajalli and Shokrpour (2014).

Pakistani Editorials (PEs) were normally seen as signed and reflected institutional opinion. Therefore, the editorials were taken from online Pakistani English newspaper editorials (PENE) for this study. The selected editorials were semi-signed by the number of editors and they might be anticipated to reflect the editor's personal opinion. In Pakistani context, therefore, unsigned editorials are taken as independent writing. The writer who marks sign on a specific article, the point of view of any paper on certain problems by the writer is reflected and the content is conceived responsible in the paper. Reynolds (2000) sees an editorial as a mixture of argument, description and a narrative in which the argument exposes. These three qualities (i.e. argument, description and narrative) have been considered in this study to explore metadiscourse features.

Many studies investigated editorial discourse. For instance, editorial structures were analyzed in the presence of a unit called 'triad: three part structures' (Bolivar, 1994) and displayed in what way editorials were written by using three basic turns, i.e. 'the follow', 'the lead' and 'the valuate'. Van Dijk (1995) 
also studied the stuff of editorials. He studied discourse and socially shared mental depictions through particular attention to the discursive expression of ideologies. Similarly, Le (2004) analyzed the language of editorials and identified different participants i.e. (1) the editorialist, (2) the audience, and (3) the people, related to the problems mentioned. She focused on the identification of participants in the editorials and analyzed their effects on persuasive process. These studies emphasized on the language, structure and content of editorials. The focus of this study is on interpersonal language of editorials, it is supposed to be MFs practiced in PENE. In editorials, the writers use various linguistic sources to make a relation to their readers through persuasive text.

\section{Material and Methods}

\section{Proposed Model}

This study is both qualitative and quantitative in nature. In order to cover the qualitative component of this research, a model (see Table 1) was devised to cover sub-categories of FMs which (the model) covered the maximum FM features for the analysis purpose.

Table 1

Model for this Study

\begin{tabular}{|c|c|c|}
\hline $\begin{array}{c}\text { Interactive } \\
\text { Metadiscourse }\end{array}$ & Classification & Examples \\
\hline \multirow{4}{*}{$\begin{array}{l}\text { Frame Markers } \\
\text { Hyland (2005) }\end{array}$} & Sequencing & e.g. accordingly, even though, on the contrary \\
\hline & Label Stages & $\begin{array}{l}\text { e.g. now, in short, at this stage, for the moment } \\
\text { in brief }\end{array}$ \\
\hline & Announce goal & e.g. Aim, desire to, in this part, here I do this \\
\hline & Topic shifts & e.g. Digress, back to, in regard to, to look more \\
\hline
\end{tabular}

\section{Formation of the List of Metadiscourse Markers (MMs)}

This study designed individual MMs that belonged to Hyland's (2005) model. For such category, the lists of FMs were devised by using two different sources i.e. (a) Hyland's (2005) book "Metadiscourse: Exploring Interaction in Writing" and online software textinspector.com. After refining the final lists, both lists were merged together and duplicate markers were removed from the final list of categories such as FMs as an interactive category (see Table 2).

Table 2

Metadiscourse Markers' Lists

\begin{tabular}{cccccc}
\hline Categories & \multicolumn{2}{c}{ Sub-Categories } & Textinspector & $\begin{array}{c}\text { Hyland's } \\
\text { book }\end{array}$ & Merged Markers \\
\hline \multirow{2}{*}{$\begin{array}{c}\text { Interactive } \\
\text { Metadiscoursi }\end{array}$} & \multirow{2}{*}{$\begin{array}{c}\text { Frame } \\
\text { Markers }\end{array}$} & Sequencing & 39 & 26 & 52 \\
\cline { 3 - 6 } & & Label stages & 12 & 16 & 22 \\
\cline { 3 - 6 } & Announce & 19 & 15 & 34 \\
\hline
\end{tabular}




\begin{tabular}{ccccc} 
& \multicolumn{2}{l}{ goals } & & \\
& Shift topic & 0 & 13 & 13 \\
\hline \multirow{2}{*}{ Total } & & $\mathbf{7 0}$ & $\mathbf{7 0}$ & $\mathbf{1 2 1}$ \\
\hline
\end{tabular}

The column of merged markers was developed by removing duplicate markers. The total 121 individual FMs were finalized for the data analysis. The final list was provided for the data analysis (see Table 3).

Table 3

List of Interactional Metadiscourse Category: Frame Markers

\begin{tabular}{|c|c|c|c|c|c|}
\hline \multirow{17}{*}{ 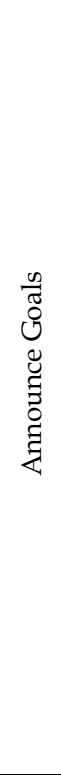 } & (in) this chapter & I wish & & to start with & First \\
\hline & (in) this part & I would like to & & (in) the $X$ part & first of all \\
\hline & (in) this section & in this chapter & & (in) chapter $X$ & Firstly \\
\hline & Aim & in this section & & (in) the $X$ chapter & Five \\
\hline & desire to & intend to & & (in) section $X$ & Four \\
\hline & Focus & Intention & & (in) this section & Fourth \\
\hline & Goal & my goal is & & (in) the $\mathrm{X}$ section & Fourthly \\
\hline & here I do this & my purpose & & (in) this chapter & Hence \\
\hline & here I will & Objective & & (in) this part & However \\
\hline & I argue & Purpose & & (in) part $X$ & Last \\
\hline & I discuss & seek to & & Accordingly & Lastly \\
\hline & I intend & want to & త్ర & Also & leads to \\
\hline & I propose & we will emphasise & $\stackrel{\overrightarrow{ \pm}}{2}$ & Although & Nevertheless \\
\hline & I seek & we will focus on & ஸे & Besides & Nonetheless \\
\hline & I suggest & wish to & & even though & Next \\
\hline & I will emphasise & would like to & & Fifthly & on the contrary \\
\hline & I will focus on & & & Fifty & Finally \\
\hline \multirow{15}{*}{ 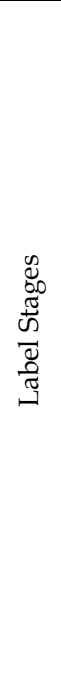 } & all in all & to summarize & & on the other hand & Though \\
\hline & at this point & to conclude & & Or & Three \\
\hline & at this stage & to repeat & & Secondly & Thus \\
\hline & by far & to sum up & & Second & Two \\
\hline & for the moment in brief & Summarize & & Subsequently & to begin \\
\hline & in conclusion & thus far & & Third & Whereas \\
\hline & in conclusion in short & & & Then & While \\
\hline & in sum & & & Thirdly & Yet \\
\hline & in summary & & \multirow{7}{*}{ 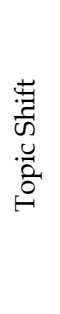 } & back to & shift to \\
\hline & Now & & & Now & turn to \\
\hline & on the whole & & & move on & to look more closely \\
\hline & on the whole overall & & & in regard to & Well \\
\hline & Overall & & & return to & Resume \\
\hline & so far & & & Digress & Revisit \\
\hline & Summarise & & & So & \\
\hline
\end{tabular}

\section{Corpus Development}

This study developed four corpora from 1000 editorials published online in Pakistani newspapers i.e. Dawn News (DN), The News (TN), The Express Tribune 
(TET) and The Frontier (TF) (250 editorials were selected from each newspaper). In this regard, a number of characteristics were considered i.e. (1) issue on daily basis, (2) related with different networks of the newspaper or contained different publishers, (3) were partially signed and partially unsigned, and were written the editorialists who represented the editorial board and to some extent individuals, (4) were argumentative and critical in nature, (5) were written in English language, and (6) were available online on newspaper websites i.e. www.dawn.com for DN, www.tribune.com.pk for TET, www.thefrontierpost.com for $T F$, and www.thenews.com.pk for TN.

\section{Corpus Retrieval}

The corpora were retrieved and processed in five stages. At the first stage, the NEs were retrieved manually in MS word files from online sources. Second stage involved the recording of the metadata in excel to mark files number, word types, token types, corpus source, title, publication date, and the names of the editorialists. At third stage, the word files were renamed for the editorial identification. The fourth stage was about removing: the publication date, the authors' name and editorial titles. At the fifth stage MS word files were converted into notepad files manually. At the sixth stage, all editorials were gathered in a single folder that was renamed as "All Editorials (1-1000)". Corpora length and distribution is given in Table 4.

Table 4

Corpora Length and Distribution

\begin{tabular}{ccc}
\hline No. of Newspapers & Token Words & Type Words \\
\hline Dawn News & 103,596 & 10,053 \\
\hline The Express Tribune & 93,048 & 9,737 \\
\hline The Frontier & 172,878 & 14,812 \\
\hline The News & 103,860 & 9,633 \\
\hline Total Corpora Length & $\mathbf{4 7 3 , 3 8 2}$ & $\mathbf{4 4 , 2 3 5}$ \\
\hline
\end{tabular}

\section{Corpus Analysis}

To analyze the corpora a number of components i.e. design of the study, instrument, and developed expressions of MFs and procedure of data analysis were considered.

\section{Design of the Study}

All of the NEs were at first downloaded from online sources and then were examined under the new proposed model of metadiscoursal categories: interactive and interactional markers. 


\section{Instrument for Data Analysis}

This study has practiced Hyland's (2005) model "Interpersonal metadiscourse" for data analysis. Such model contained two categories: interactive and interactional. This study has particularly followed interactive category in which one of the sub-categories is frame markers, has been studied for data analysis.

\section{Expressions Developed for Metadiscourse Features}

Expressions of each metadiscoursal category (see Table 5) were developed which were later processed in the software Antconc.3.4.4.0 to have numerical results. The significance of these expressions made a new way for the future researches. In order to have an innovative way, the markers were devised in the form of expressions and they were used in order to check all the required MMs at once. This saved the time of the researchers and kept them away from discrepancies during the analysis process.

Table 5

\section{Expressions Developed for Metadiscourse Features}

\begin{tabular}{|c|c|c|c|}
\hline \multirow{4}{*}{\multicolumn{2}{|c|}{ }} & One word & $\begin{array}{l}\text { Accordingly | also | although | besides | fifthly | fifty | finally | first | firstly | five } \\
\text { four | fourth | fourthly | hence | however | last | lastly | nevertheless | (a) | (b) | (c) } \\
\text { (d) | nonetheless | next | (1) | (2) | (3) | (4) | second | or | subsequently | secondly } \\
\text { then | secondly | third | though | three | thus | two | whereas | while | yet | thirdly }\end{array}$ \\
\hline & & Two word & even though | leads to | to begin \\
\hline & & Three word & $\begin{array}{l}\text { to start with | in part * | in chapter } * \text { | in section * | in this chapter | in this part | in this } \\
\text { section | first of all | on the contrary }\end{array}$ \\
\hline & & Four word & in the ${ }^{*}$ part | in the * chapter | in the ${ }^{*}$ section | in the * chapter | on the other hand \\
\hline \multirow{13}{*}{ 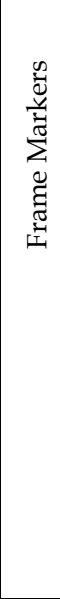 } & \multirow{5}{*}{ 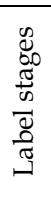 } & One word & Now | overall | summarise | summarize \\
\hline & & Two word & $\begin{array}{l}\text { by far | in conclusion | in short | in conclusion | in summary | in sum | so far | to } \\
\text { conclude | thus far | to repeat | to conclude | to summarize }\end{array}$ \\
\hline & & Three word & at this point | all in all $\mid$ at this stage $\mid$ on the whole | to sum up \\
\hline & & Four word & on the whole | overall \\
\hline & & Five word & for the moment $\mid$ in brief \\
\hline & \multirow{4}{*}{ 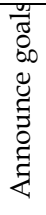 } & One word & Aim | focus | goal | intention | objective | purpose \\
\hline & & Two word & $\begin{array}{l}\text { desire to | I argue | I discuss | I intend | I propose | I seek | I suggest | I wish | intend } \\
\text { to | my purpose | seek to | want to | wish to }\end{array}$ \\
\hline & & Three word & $\begin{array}{l}\text { in this part | in this chapter | in this section | here I will | I will emphasise | in this } \\
\text { section | my goal is | we will emphasise | in this chapter | would like to }\end{array}$ \\
\hline & & Four word & here I do this | I will focus on | I would like to | we will focus on \\
\hline & \multirow{4}{*}{ 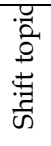 } & One word & 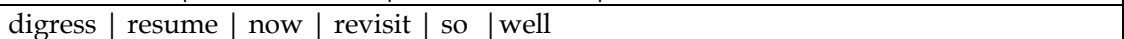 \\
\hline & & Two word & back to | move on | return to | shift to | turn to \\
\hline & & Three word & in regard to \\
\hline & & Four word & to look more closely \\
\hline
\end{tabular}

\section{Corpus Analysis Procedure}

Corpus analysis was carried in a number of steps. First of all the data was retrieved from online sources (see 3.3). In order to develop MMs, the software 'Textinspector.com' as a source was used to develop the lists of MFs for analysis. Then, for critical analysis and for minute observation, the corpus was analyzed manually. For the purpose of checking frequencies of metadiscourse devices and the analysis of data, the text processor (Antconc.3.4.4.0, 2014) was used. Then, the 
items taken to be metadiscourse were identified and categorized in the texts based on the proposed model of metadiscourse (see Table 1) which contained the said categories, and the analysis found all MMs which were used most frequently and less frequently in interactive and in interactional categories, but ignored those markers which were not found even a single time in a single file of the corpus.

\section{Tuning Procedure}

For finding frequencies, the self-made corpus expressions (see Table 5) in software (Antconc.3.4.4.0, 2014) were studied that helped to record all the required frequencies of FMs after setting the parameters i.e. going to cluster/N-Grams, keeping minimum frequency 1 , minimum range 1 and 2 for convenience, minimum cluster size 1, and maximum cluster size 1 and 2 for convenience in noticing results. As sorted by word, the frequencies were easily counted as numerical results. In the end, a few precautions were observed while analyzing each corpus, and a few words e.g. 'state' and 'may' were not considered in data analysis because they caused impurity in the data.

\section{Results and Discussion}

This study has explored the numerical frequencies of MMs from the selected newspapers editorials and then have been classified into propositional and metadiscourse (non-propositional). See table below.

Table 6

Distribution of the Frequencies of Interactive Markers

\begin{tabular}{ccc}
\hline \multirow{2}{*}{ No. of Newspapers } & \multicolumn{2}{c}{ Interactive Markers } \\
\cline { 2 - 3 } & \multicolumn{2}{c}{ Frame Markers } \\
\cline { 2 - 3 } & Propositional & Metadiscourse \\
\hline Dawn News & 3,048 & 4,840 \\
\hline The Express Tribune & 2,459 & 4,646 \\
\hline The Frontier & 4,585 & 8,153 \\
\hline The News & 3,319 & 1,637 \\
\hline
\end{tabular}

As far as interactive metadiscourse results are concerned, the frequency of frame markers is seen in all editorials but the greater amount of interactive markers is found in the corpus of ' $\mathrm{TF}^{\prime}$ '. On the other hand, in corpus of ' $\mathrm{TF}^{\prime}$ in which the most frequent sub-category 'sequencing markers' has been observed. The results of frame markers in each corpus are given in Table 7.

Table 7

Detailed Distribution of Frame Markers

\begin{tabular}{|c|c|c|c|c|c|c|c|c|c|}
\hline \multirow{2}{*}{$\begin{array}{l}\text { Interactive } \\
\text { Category }\end{array}$} & \multirow{2}{*}{$\begin{array}{c}\text { Sub- } \\
\text { Categories }\end{array}$} & \multicolumn{2}{|c|}{ The Frontier } & \multicolumn{2}{|c|}{ The Dawn } & \multicolumn{2}{|c|}{ The Express Tribune } & \multicolumn{2}{|c|}{ The News } \\
\hline & & Pro & Meta & Pro & Meta & Pro & Meta & Pro & Meta \\
\hline Fra & Sequencing & 170 & 2,230 & 369 & 1,237 & 398 & 900 & 494 & 1,186 \\
\hline Markers & Label Stages & 13 & 253 & 103 & 75 & 0 & 190 & 20 & 97 \\
\hline
\end{tabular}




\begin{tabular}{|c|c|c|c|c|c|c|c|c|}
\hline $\begin{array}{c}\text { Announce } \\
\text { goal }\end{array}$ & 10 & 127 & 23 & 73 & 8 & 71 & 27 & 54 \\
\hline Topic shifts & 130 & 480 & 126 & 292 & 155 & 283 & 81 & 171 \\
\hline Total & 4,585 & 8,153 & 3,048 & 4,840 & 2,459 & 4,646 & 3,319 & 4,732 \\
\hline
\end{tabular}

\section{Frame Markers}

The term 'frame markers' refers to sequences, text stages, or discourse acts. These markers frame the propositional material in order to make it interesting and attractive for the readers. By the use of these markers, the writer makes his writing beautiful, conveys his goals and gives the sequence of ideas appropriately. Frame markers such as 'finally', 'to conclude', 'the aim', 'I would like to', 'I wish', 'firstly' have been seen in the corpora (see examples 1-10). In this study, FMs are further subcategorized into announce goals, sequencing, labeling and topic shifting.

\section{Announce Goals}

These are frame makers that announce discourse goals. In this study, FMs have been seen as being persuasive and more attentive for the readers. Through such markers (see examples 1 and 2), the reader's mind may be manipulated as per the writer's view.

1) Sometimes it seems that the aim instead is to stir up anger and push the blame elsewhere. If the Afghan president wants to take Pakistan to the UN over support of the Taliban, more buried ghosts will be brought to the table. (The New file no. 21)

2) Lastly, I would like to get something straight. While Egypt is on the path to democracy the road remains long and strewn with boulders, as the president admits (File no. 190 in TF).

In examples 1 and 2, the use of 'the aim' and 'I would like to' has been seen in this study which has shown the writer's intentions that how he foregrounds the reader and lets the reader to figure out the significance of the propositional material. These markers have been employed by the writer to announce goals and purposes personally.

3) So now comes the general election. I wish I could say that it will be a battle of ideas. But it mostly won't, and not just because Trump doesn't have any coherent policy ideas (File no.53 in TF).

Similarly, in example 3 the use of 'I wish' has shown the wishes that he actually has about the general elections. The writer is going to say indirectly that he is seeing the battle of ideas that are about to start soon. In this way, this marker has announced the goal of the writer explicitly. Such kind of use of these markers is considered as a metadiscourse. 


\section{Sequencing}

Sequencing markers (see example 4) are useful in sequencing the text's parts or ordering an argument internally i.e. explicit additive relations.

4) Preservation of history has two major benefits: firstly, it shows that we value our heritage and are concerned about holding on to it (File no. 35 in $\mathrm{DN}$ )

In example 4, the writer has used a sequence marker making the writing more dimensional and directional for the readers. The use of 'firstly' shows the writer's opinions that how he has organized different arguments and ideas through the said marker. The most crucial aspect by the use of such marker (sequencing) has sequenced the propositional material by making it more persuasive and interesting for the readers.

5) The segments of the formal economy that have performed have been taxed heavily. On the other hand, development seems to be restricted to one province and even their projects have not really aided job growth (File no. 96 in TET)

6) Raising tax rates to increase revenue is, however, one strategy it has consistently followed (File no. 210 in TET)

In examples 5 and 6, 'on the other hand' and 'however' have been employed to show the well execution of the propositional stuff by the writer. The purpose of such markers is to create logical connection and to show the explicit meanings to the readers. Such markers guide the readers to understand the writer's stance through his writing.

\section{Label Stages}

These are FMs that explicitly label text stages. Discourse-labels are used (e.g., in summary, thus far) to mark the stages of textual development.

7) All in all, the situation in Syria has worsened considerably, fighting has intensified, and the fragile ceasefire is on the verge of breaking down unless the US and Russia step in to prevent that from happening (File no. 223 in TF).

8) This is not how an economy is spurred into action. The government's economic policy should be focusing on inclusive growth. So far, that has not been the case (File no. 73 in TET).

In examples 7 and 8, the use of 'all in all' and 'so far' have been observed while analyzing the corpora. These markers have exposed the position of the ideas 
in propositional material. The writer has brought these markers into the use to make his writing more interesting and dimensional for the readers. In this way, the writer has guided the readers about the propositional stuff and showed internal logical connections with the help of these markers.

\section{Topic Shifts}

These FMs indicate shifts in a topic. For this purpose different topicalizers (e.g., concerning, in regard to) are uses to indicate the shifting from one idea to another.

9) TRC was constituted by Finance Minister Ishaq Dar about two years back to recommend measures to reform the tax collection as well as tax machinery (File no. 69 in TN).

10) It is our turn to put our hands to our mouth -- in disbelief. The members of the National Assembly say they are forced to live on an -almost -- shoestring budget (File no. 207 in DN)

In examples 9 and 10, the writer has used 'back to' and 'turn to' as MMs which help in shifting topics. These markers have simply helped the writer to put the reader back to certain point that has already been discussed or may have been discussed for a few times. Through such markers, the writer has grabbed the attention of the readers in his hands wherever he wants to see the readers. The use of such markers has pushed the reader back to another point leaving the current matter for a certain time period. All of these markers are considered as metadiscourse because the writer has intentionally employed such markers to well organize his writing for readers' sake.

In short, the use of FMs has been employed to organize the text logically. FMs have performed multiple functions as above mentioned. All of these subcategories are assembled under FMs that are in themselves categorized under interactive metadiscourse.

\section{Conclusion}

From the results, it is clear that the editorials in The Frontier contain the excessive amount of frame markers in comparison with the editorials in Dawn News, The Express Tribune and The News. In more detail, the excessive amount of frame markers have been explored in the editorials in The Frontier in terms of propositional and metadiscourse markers. It is inferred that such an excessive use of frame markers as metadiscoursal features organize the text of editorials purposefully for delivering the intended meanings, while the editorials from the rest of the newspapers contain rather less number of frame markers. To organize the text effectively, the editorials in The Frontier find the abundant use of sequencing markers. It implicates in the benefit of upcoming editors being 
professional and persuasive. Secondly, it can be beneficial in English for specific purposes and can be used to inform the readers or audience for understanding the agendas behind the narratives being established by the editorial writers. 


\section{References}

Bateson, G. (1972). Steps to an ecology of mind: Collected essays in anthropology, psychiatry, evolution, and epistemology. Chicago and London: University of Chicago Press.

Beaugrande de, R., \& Dressler W. U. (1981). Introduction to text linguistics. London, NY: Longman.

Bolivar, A. (1994). The structure of newspaper editorials. In M. Coulthard (ed.), Advances in Written Text Analysis (pp. 276-294). London: Routledge.

Cheng, X., \& Steffensen, M. S. (1996). Metadiscourse: A technique for improving student writing. Journal of Research in the Teaching of English, 30(2), 149-181.

Goffman, E. (1974). Frame analysis: An essay on the organization of experience. Cambridge, Mass: Harvard University Press.

Gholami, M., Tajalli, G., \& Shokrpour, N. (2014). An investigation of metadiscourse markers in English medical texts and their Persian translation based on Hyland's model. European Journal of English Language and Literature Studies. 2(2), $1-41$.

Hyland, K. (2000). Disciplinary discourses: Social interactions in academic writing. London: Longman.

Hyland, K., \& Tse, P. (2004). Metadiscourse in academic writing: A reappraisal. Applied Linguistics, 25(2), 156-177.

Hyland, K. (2005). Metadiscourse: Exploring interaction in writing. London: Continuum.

Nystrand, M. (1986). The structure of written communication. Orlando: Academic Press.

Oskouei, L. K. (2011). Interactional variation in English and Persian: A comparative analysis of metadiscourse features in magazine editorials (doctoral dissertation). School of Language and Communication Studies, University of East Anglia, Norwich, England.

Reynolds, M. (2000). The blending of narrative and argument in the generic texture of newspaper editorials. International Journal of Applied Linguistics, 10(1), 25-40.

Siddique, A. R. (2017). Metadiscourse analysis of Pakistani English newspapers editorials: A corpus-based study (unpublished master thesis). Department of Applied Linguistics, Government College University, Faisalabad, Pakistan. 
Siddique, A. R., \& Mahmood, A., \& Iqbal, J. (2018). Metadiscourse analysis of Pakistani English newspapers editorials: A corpus-based study. International Journal of English Linguistics, 8(1), 146-163.

Thompson, G. (2001). Interaction in academic writing: Learning to argue with the reader. Applied Linguistics, 22(1), 58-78.

Van Dijk, T. A. (1995). Opinions and ideologies in editorials. Paper Presented at the 4th International Symposium of Critical Discourse Analysis: Language, Social Life and Critical Thought (14-16 December). Athens, Greece.

Williams, J. M. (1981). Style: Ten lessons in clarity and grace. Boston: Scott Foresman.

Yazdani, S., Sharifi, S., \& Elyassi, M. (2014). Exploring hedges and boosters in 9/11 English front page news articles. Asian Journal of Research in Social Sciences and Humanities, 4(3), 301-313. 